cancer, heart diseases, renal diseases, and diabetics based on workers exposure profile.

\section{P-31 FACTORS ASSOCIATED WITH MUSCULOSKELETAL SYMPTOMS IN WORKING WOMEN OF FLOWER CROPS OF LA SABANA NORTH OF CUNDINAMARCA.}

${ }^{1}$ Aanh Eduardo Dimate Garcia, Diana Carolina Rodríguez Romero, Caludia Marcela Sabogal Fajardo, José Vicente Orduz Camacho. ${ }^{1}$ Fundación Universitaria del Área Andina, Colombia

\subsection{6/OEM-2021-EPI.170}

Introduction Musculoskeletal disorders are multifactorial and a public health problem. They occur in different production sectors, but information is scarce in the flower-producing industry.

Aim To analyze factors associated with musculoskeletal symptoms in floriculture workers of the northern savannah of Cundinamarca in 2016.

Materials and Method This cross-sectional study was carried out in a non-random sample of 84 cultivators (production, packing and storage) of ornamental flowers for export in the savanna north of Cundinamarca. The sociodemographic variables, the informed consent and the Nordic questionnaire were obtained through a survey. Statistical analyses were performed in SPSS version 24.

Results Participating women had a mean age of 41.744 (SD = 10.64) and seniority in the development of activities between 1 to 27 years. Statistically significant correlations were found between head/eye symptoms and active pauses $r=-0.491$, $p$ $<0.05$; neck and race $\mathrm{R} 0.234 \mathrm{p}<0.05$; neck and have free time at home $\mathrm{r}=-0.391, \mathrm{p}<0.01$; Shoulder and workplace (less exposure) $\mathrm{r}=-0.257, \mathrm{p}<0.05$; wrist hand and active pauses $\mathrm{r}=-0.283, \mathrm{p}<0.01$, active pauses with stretching (exposure) $\mathrm{r}=0.283, \mathrm{p}<0.01$; upper back and have time for active breaks $\mathrm{r}=-0.218, \mathrm{p}<0.05$; upper back and being able to sit up during breaks $\mathrm{r}=0.255, \mathrm{p}<0.05$; upper back and have free time at home $\mathrm{r}=-0.235, \mathrm{p}<0.05$; right knee and lifting load $\mathrm{r}=0.323, \mathrm{p}<0.01$; right knee and have free time at home $\mathrm{r}=-0.391, \mathrm{p}<0.01$.

Conclusion Findings indicate positive correlations between race, sitting during breaks, lifting, and musculoskeletal symptoms; and negative correlations between taking active breaks, having free time at home, workplace, taking active breaks, taking active breaks with stretching, having time for active breaks, having free time at home, and musculoskeletal symptoms in flower women.

\section{P-36 ORGANIZATIONAL INDICES OF BURNOUT INVOLVING NATURE OF TASK, HAZARD EXPOSURE, AND NATURE OF MANAGEMENT AMONG FEMALE FACTORY WORKERS}

${ }^{1}$ Jinky Leilanie Lu. 'National Institutes of Health, University of the Philippines, Philippines

\subsection{6/OEM-2021-EPI.171}

Objectives This study aims to look at the organizational indices of 'burnout' among Filipino female factory workers in the Philippines. They have been faced with multiple work arrangements coupled by exposure to hazards in the workplace that may compound their perception and experience of burnout.
Methods Secondary analysis on a research study was conducted on a wide range of socio-demographic, health and occupational data on 344 female factory workers. The database was a cross-sectional study involving 344 female factory workers. Multiple logistic regressions were used to study the overall association of interest, simultaneously controlling for all confounders.

Results The results of the study showed that $60 \%$ of female workers reported burnout. The highest mean scores for nature of tasks were obtained for repetitive works (1.3172 \pm $0.8905)$, and works that regularly require new quality (1.6193 \pm 0.7628 ). In terms of self-reported illnesses, the following yielded the highest means which implies greater occurrence; headaches $(0.7733 \pm 0.4193)$, body aches $(0.7442 \pm 0.4370)$, and coughs and colds $(0.6948 \pm 0.4612)$. The number of illnesses in the last 6 months was found to be associated with organizational correlates of burnout namely- Nature of Task Component 1 ( $\beta=1.298 ; \mathrm{p}<0$.01); Job Autonomy Component $1(\beta=1.112 ; p<0$.05); Workplace Hazards Component 1 (fumes, vapors, noise) ( $\beta=1.147 ; \mathrm{p}<0$.01); Workplace Hazards Component 2 (odors, high temperatures) $(\beta=1.153$; $\mathrm{p}<0.05)$; and Workplace Hazards 3 (dust, standing) $(\beta=1.091 ; p<0$.01). It was observed that an increase of 1 in the score for Workplace Hazards 1 implies 121.4\% increase in the odds of having sickness often as opposed to seldom. Conclusion The results of this study revealed that the nature of a factory worker's work is causing burnout and adverse health.

\section{P-40 OCCUPATIONAL EXPOSURE TO PESTICIDES AMONG VEGETABLE FARMERS IN AKUAPEM NORTH MUNICIPALITY}

${ }^{1}$ Maame Serwa Opare-Boafo, Joseph Richmond Fianko. 'University of Ghana, Ghana

\subsection{6/OEM-2021-EPI.172}

Introduction According to the Stockholm convention on persistent organic pollutant, 9 of the 12 most dangerous persistent chemicals are pesticides (Chekroun et al., 2014).

Objectives To assess knowledge, practice and attitudes regarding safe use of pesticides and toxicity awareness among vegetable farmers.

Methods A cross-sectional study of 100 vegetable farmers was conducted between November to December 2016. Data collection involved administration of standardized questionnaire to farmers on knowledge, safe use of pesticides and toxicity awareness.

Results Results of the field survey indicated that 48\% (95\% $\mathrm{CI}=38-58)$ did not use any protective clothing such as googles, gloves, long boots. Among the respondent 93\% (95\% $\mathrm{CI}=85-96)$ go back to the farm in less than 24 hours after pesticide application. As a result of pesticide exposure, about $67 \%(95 \% \mathrm{CI}=56-75)$ of farmers experienced various kind of discomfort including headache, tingling or burning of skin, irritation of skin and or eye. Most farmers 65\% (95\% CI 5473). Apply pesticides in mixtures that is farmers mix pesticides with different active ingredients in one machine for application. Farmers were exposed to 12 pesticides active ingredient. Conclusion Based on the analyses it can be concluded that most of farmers' involved in vegetable farming in the Akwapim North Municipality are in the middle age group. Almost all the farmers use pesticides in their farming activities. 